\title{
GCMS ANALYSIS OF ENDOPHYTIC FUNGI CURVULARIA AERIA MTCC-12847 ISOLATED FROM TRIBULUS TERRESTRIS L.
}

\author{
KAMANA SAHANI ${ }^{*}$, DEEPENDRA THAKUR ${ }^{2}$
}

${ }^{1}$ Department of Microbiology, Andhra University, Visakhapatnam, India, ${ }^{2}$ Department of Microbiology, Banglore University, Banglore, India Email: kmnsahani@gmail.com

Received: 12 Jul 2018 Revised and Accepted: 15 Feb 2019

\begin{abstract}
Objective: The objective of the present investigation was to perform the Gas Chromatography-mass spectrometry (GCMS) analysis of endophytic fungi Curvularia aeria MTCC-12847 isolated from Tribulus terrestris L. to find out the active compound present in the extract.

Methods: The endophytic fungi were isolated from the plant Tribulus Terrestris L., leaf which was cultivated in optimized media for the production of secondary metabolites and was extracted using ethyl acetate. Ethyl acetate extract was used for the Gas Chromatography-mass spectrometry
\end{abstract} (GCMS) analysis.

Results: GC-MS analysis of ethyl acetate extract of endophytic fungi revealed the presence of various secondary metabolites, the highest amount present was Palmitic acid (24.54\%) and Lowest was Dimethyl 1-phenyl-7-methyl-1-hydroxy-1,4-dihydronaphthalene-2,3-dicarboxylate (5.76\%).

Conclusion: The endophytic fungal Curvularia aeria MTCC-12847 extract isolated from the Tribulus terrestris L. shows the presence of various bioactive compounds.

Keywords: Endophytic fungi, Tribulus terrestris L., GCMS analysis

(C) 2019 The Authors. Published by Innovare Academic Sciences Pvt Ltd. This is an open access article under the CC BY license (http://creativecommons.org/licenses/by/4.0/) DOI: http://dx.doi.org/10.22159/ijpps.2019v11i4.28440

\section{INTRODUCTION}

Tribulus terrestris $\mathrm{L}$., belonging to the family Zygophyllaceae is a wellknown shrubby plant in various traditional systems of medicine including Ayurveda, Siddha, and Unani. The plant is commonly known as "Caltrops" and found all over India up to $11,000 \mathrm{ft}$. height and widely grown in Kashmir, Rajasthan and all warm regions of both hemispheres [1]. According to Traditional Chinese Medicine (TCM), the plant is considered as an aphrodisiac and reported to stimulate sexual behavior of men, strengthen the heart muscle and reduce the level of cholesterin [2]. The fruit is commonly used to treat vitiligo, eye and abdominal diseases [3]. T. terrestris is commonly used in folklore medicine as tonic, analgesic, astringent, stomachic, antihypertensive, diuretic and urinary anti-infective. Sapogenins like diosgenin, gitogenin, chlorogenin were reported in the plant and the flavonoids contained in the fruit are said to be used for the treatment of gout [1].

Recently, various studies were conducted to evaluate the pharmacological properties of T. terrestris. The anti-arthritic activity of T. terrestris was analyzed using Freund's complete adjuvant (FCA) induced arthritis in rats [4]. The plant extract inhibited the carrageenan-induced inflammation in rats [5] by suppressing the expression of various inflammatory cytokines [6]. The anticariogenic activity of this plant against Streptococcus mutans was reported [7]. The protective effect of tribulosin isolated from $T$. terrestris against cardiac ischemia/reperfusion injury and its underlying mechanism was also studied [8]. There is evidence for the antiproliferative effect of T. terrestris saponins on mouse carcinoma [9] and breast cancer [10]. The saponin fraction from T. terrestris was found less toxic to normal human fibroblasts [11]. The anti-carcinogenic effect of $T$. terrestris on DMBA induced papilloma in mice [12] was also reported.

Endophytes are the group of microorganisms that reside in plants within their intercellular spaces without causing any negative symptoms to their host plant [13]. Endophytes are extremely diverse fungi [14] bacteria [15] or actinomycetes [16]. Endophytic strains have potential to secret secondary metabolites that protect plants against insects, pests and other pathogenic organisms [17] thus endophytes represent a promising source of novel bioactive compounds for pharmacological and agricultural applications [18]. Different investigators have reported that a wide variety of secondary metabolites have been obtained from the endophytic microbes [19]. Considering the medicinal activity, traditional information and various experimental evidence, the present study evaluated the phytochemical constituents of endophytic fungi isolated from T. terrestris by Gas Chromatography-mass spectrometry (GCMS) analysis.

\section{MATERIALS AND METHODS}

\section{Collection of plant material}

Visakhapatnam (Location $17^{\circ} 40^{\prime} 48.32^{\prime \prime} \mathrm{N}, 83^{\circ} 12^{\prime} 5.8^{\prime \prime} \mathrm{E}$.) is situated between the Eastern Ghats and the Bay of Bengal. The annual mean temperature ranges between $24.7-30.6{ }^{\circ} \mathrm{C} \quad\left(76-87{ }^{\circ} \mathrm{F}\right)$, with the maximum in the month of May and the minimum in January; the minimum temperatures range between $20-27^{\circ} \mathrm{C}\left(68-81^{\circ} \mathrm{F}\right)$ and the average annual rainfall recorded is $1,118.8 \mathrm{~mm}$. The plant was located in the Campus of Andhra University. Healthy and mature plant of Tribulus terrestris L. was collected from the Campus, Andhra University. Samples were tagged and placed in separate sterile polythene bags, brought to the laboratory and processed within $24 \mathrm{~h}$ of collection [20,21]. Fresh plant material was used for the isolation work to reduce the chance of contamination. Sample collection was done in January 2016 and the plant used in the study was authenticated by Prof. S. B. Padal (Botanist), Department of Botany, Andhra University, Visakhapatnam and the plant material was also deposited in Botany Department herbarium (AUV), Andhra University, Visakhapatnam with Voucher specimen numbers-22294.

\section{Isolation of endophytic fungi}

The sample was washed thoroughly in running tap water before processing. Leaf samples were surface sterilized by dipping in $70 \%$ ethanol (v/v) for $1 \mathrm{~min}$ and $3.5 \% \mathrm{NaOCl}(\mathrm{v} / \mathrm{v})$ for $3 \mathrm{~min}$, rinsed thrice with sterile water and dried. Bits of $1.0 \times 1.0 \mathrm{~cm}$ size were excised with the help of a sterile blade. Two hundred segments of Tribulus terrestris L. leaf segments were placed on the water agar (16\%) (WA) medium supplemented with Streptomycin $(100 \mathrm{mg} / \mathrm{l}$; Sigma, St. Louis, MO, USA) were used for the isolation of endophytic fungi. The Petri dishes were sealed using parafilm and The Petri dishes were incubated at 25$27^{\circ} \mathrm{C}$ till the mycelia start growing from the samples [22]. 


\section{Secondary metabolite production of endophytic fungal isolate}

The endophytic fungus EF1 i.e. Curvularia aeria MTCC-12847 was cultured in 1-l Erlenmeyer flasks containing $500 \mathrm{ml}$ of optimized culture media (PDB) under optimized parameters (pH: 5.5-6.5, Temperature: $25{ }^{\circ} \mathrm{C}-30{ }^{\circ} \mathrm{C}$, Incubation days: 9 d) under static conditions. The culture broth was then filtered to separate the culture filtrate and mycelium. Culture filtrate was blended thoroughly and centrifuged at 4,000 rpm for $5 \mathrm{~min}$. Liquid supernatant was extracted with an equal volume of solvent thrice (Ethyl acetate) separately and was evaporated to dryness under reduced pressure at $50^{\circ} \mathrm{C}$ using rotary flash evaporator [23].

\section{Gas chromatography-mass spectrometry (GCMS) analysis of the} crude extract

The Gas Chromatography-mass spectrometry (GC-MS) analysis of the endophytic fungal extract was made using JEOL GC MATE || instrument under computer control at $70 \mathrm{eV}$. About $1 \mu \mathrm{l}$ of the ethyl acetate extract was injected into the Gas Chromatography-mass spectrometry (GC-MS) using a microsyringe and the scanning was done for $45 \mathrm{~min}$ [24-25]. As the compounds were separated, they eluted from the column and entered a detector which was capable of creating an electronic signal whenever a compound was detected. The greater the concentration in the sample, the bigger the signal obtained which was then processed by a computer. The time from when the injection was made (Initial time) to when elution occurred was referred to as the retention time (RT). While the instrument was run, the computer generated a graph from the signal called chromatogram. Each of the peaks in the chromatogram represented the signal created when a compound eluted from the gas chromatography column into the detector [26]. The X-axis showed the RT and the Y-axis measured the intensity of the signal to quantify the component in the sample injected. As individual compounds eluted from the Gas chromatographic column, they entered the electron ionization (mass spectroscopy) detector, where they were bombarded with a stream of electrons causing them to break apart into fragments. The fragments obtained were actually charged ions with a certain mass [27]. The mass/charge (M/Z) ratio obtained was calibrated from the graph obtained, which was called the mass spectrum graph which is the fingerprint of a molecule. Before analyzing the extract using GCMS, the temperature of the oven, ion chamber temperature and GC interface temperature, mass analyzer, the flow rate of the gas used and the electron gun were programmed initially. The temperature of the oven was maintained at 50 to $250{ }^{\circ} \mathrm{C} @ 10{ }^{\circ} \mathrm{C} / \mathrm{min}$. While the ion chamber temperature and GC interface temperature were maintained at $250{ }^{\circ} \mathrm{C}$. The mass analyzer used was quadruple double focusing mass analyzer. High pure Helium gas was used as a carrier as well as an eluent. The flow rate of helium was set to $1 \mathrm{ml} / \mathrm{min}$. The electron gun of mass detector liberated electrons having an energy of about 70 $\mathrm{eV}$, Photon multiplier tube was used as the detector. The column employed here for the separation of components was HP-5ms. The identity of the components in the extracts was assigned by the comparison of their retention indices and mass spectra fragmentation patterns with those stored on the computer library and also with published literature. Compounds were identified by comparing their spectra to those of the Wiley and NIST/EPA/NIH mass spectral libraries $[28,29]$.

\section{RESULTS}

The studies on the active compounds of the endophytic fungi isolated from Tribulus terrestris $\mathrm{L}$. and their ethyl acetate extract by Gas Chromatography-mass spectrometry (GC-MS) analysis clearly showed the presence of eleven compounds. The active compounds with their retention time (RT), Molecular formula, Molecular weight, and concentration (peak area \%) are presented in table 1. The GCMS chromatogram of the different peak of the compounds detected was shown in fig. 12 and different compound present (fig. 1-11).

Table 1: GCMS analysis of EF1 (Curvularia aeria MTCC-12847)

\begin{tabular}{|c|c|c|c|c|c|c|c|}
\hline $\begin{array}{l}\text { S. } \\
\text { No. }\end{array}$ & Name of compound & $\begin{array}{l}\text { Molecular } \\
\text { formula }\end{array}$ & Structure & $\begin{array}{l}\text { Molecular } \\
\text { weight }(\mathrm{g} / \mathrm{mol})\end{array}$ & Area & $\begin{array}{l}\text { Retention } \\
\text { time (RT) }\end{array}$ & $\begin{array}{l}\text { Peak } \\
\text { area }(\%)\end{array}$ \\
\hline 1. & Palmitic acid & $\mathrm{C}_{16} \mathrm{H}_{32} \mathrm{O}_{2}$ & & 256.43 & 2683164 & 17.85 & 24.54 \\
\hline 2. & Hexadecanoic acid, Z-11- & $\mathrm{C}_{16} \mathrm{H}_{30} \mathrm{O}_{2}$ & & 254.414 & 1156013 & 19.83 & 10.57 \\
\hline 3. & E,E-6,8-Tridecadien-2-ol, acetate & - & & - & 952163 & 21.42 & 8.71 \\
\hline 4. & $\begin{array}{l}\text { Tetradecanoic acid, 12-methyl-, methyl } \\
\text { ester }\end{array}$ & $\mathrm{C}_{16} \mathrm{H}_{32} \mathrm{O}_{2}$ & & 256.43 & 930079 & 17.2 & 8.50 \\
\hline 5. & 1-Eicosene & $\mathrm{C}_{20} \mathrm{H}_{40}$ & & 280.54 & 867832 & 22.25 & 7.93 \\
\hline 6. & Spirostan-9-ol, 3-amino-, (3á,5à,25R)- & - & & - & 760041 & 30.4 & 6.95 \\
\hline 7. & 9-Amino-6-fluoro-lepidine & $\mathrm{C}_{10} \mathrm{H}_{9} \mathrm{FN}_{2}$ & & 176.194 & 780936 & 14.17 & 7.14 \\
\hline 8. & Z-13-Octadecen-1-yl acetate & $\mathrm{C}_{20} \mathrm{H}_{38} \mathrm{O}_{2}$ & & 310.5145 & 742505 & 23.83 & 6.79 \\
\hline 9. & ç-Thionodecalactone & $\mathrm{C}_{10} \mathrm{H}_{18} \mathrm{OS}$ & & 186.313 & 739956 & 16.2 & 6.76 \\
\hline 10. & $\begin{array}{l}\text { 9-oxabicyclo (3.3.1) nonan-2-one, 6- } \\
\text { hydroxy- }\end{array}$ & $\mathrm{C}_{8} \mathrm{H}_{12} \mathrm{O}_{3}$ & & 156.179 & 687809 & 13.62 & 6.29 \\
\hline 11. & $\begin{array}{l}\text { Dimethyl 1-phenyl-7-methyl-1-hydroxy- } \\
\text { 1,4-dihydronaphthalene-2,3- } \\
\text { dicarboxylate }\end{array}$ & - & & - & 630650 & 28.55 & 5.76 \\
\hline
\end{tabular}


EF1

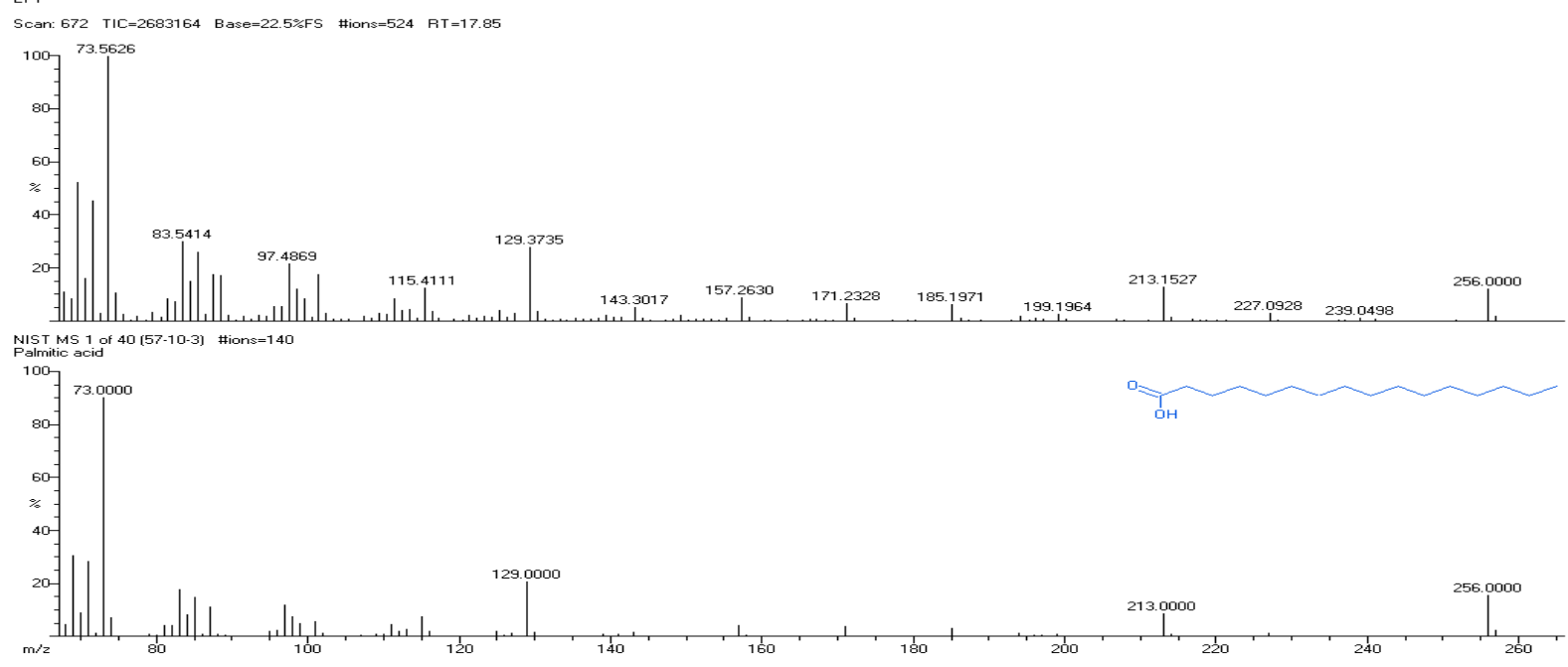

Fig. 1: Structure of palmitic acid present in EF1 (Curvularia aeria MTCC-12847) by using GCMS analysis

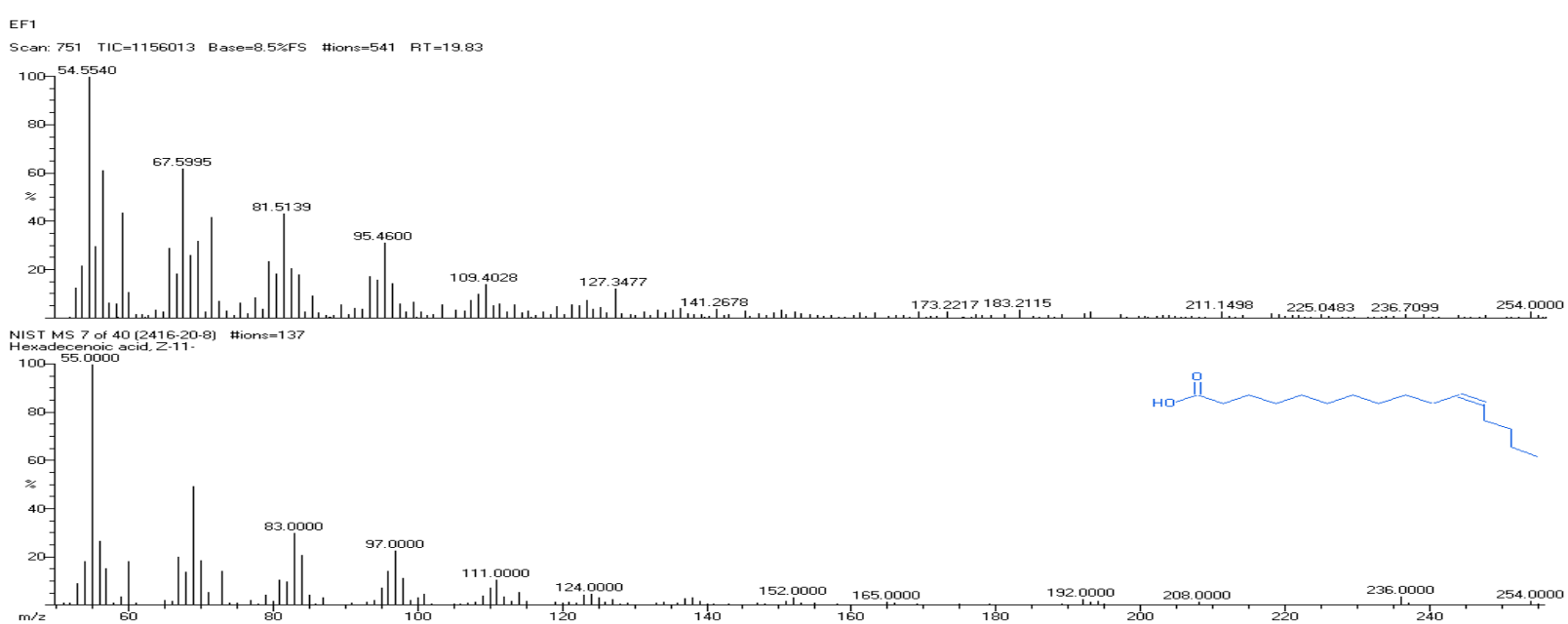

Fig. 2: Structure of Hexadecanoic acid, Z-11-present in EF1 (Curvularia aeria MTCC-12847) by using GCMS analysis

EF1

Scan: 814 TIC=952163 Base=8.5\%FS \#ilons=515 RT=21.42

(10)

$\sqrt{12}$

$\mid$

ST MS 4 of 770 [DE\# 9985] \#tions=163



Fig. 3: Structure of E, E-6, 8-Tridecadien-2-ol, acetate present in EF1 (Curvularia aeria MTCC-12847) by using GCMS analysis 


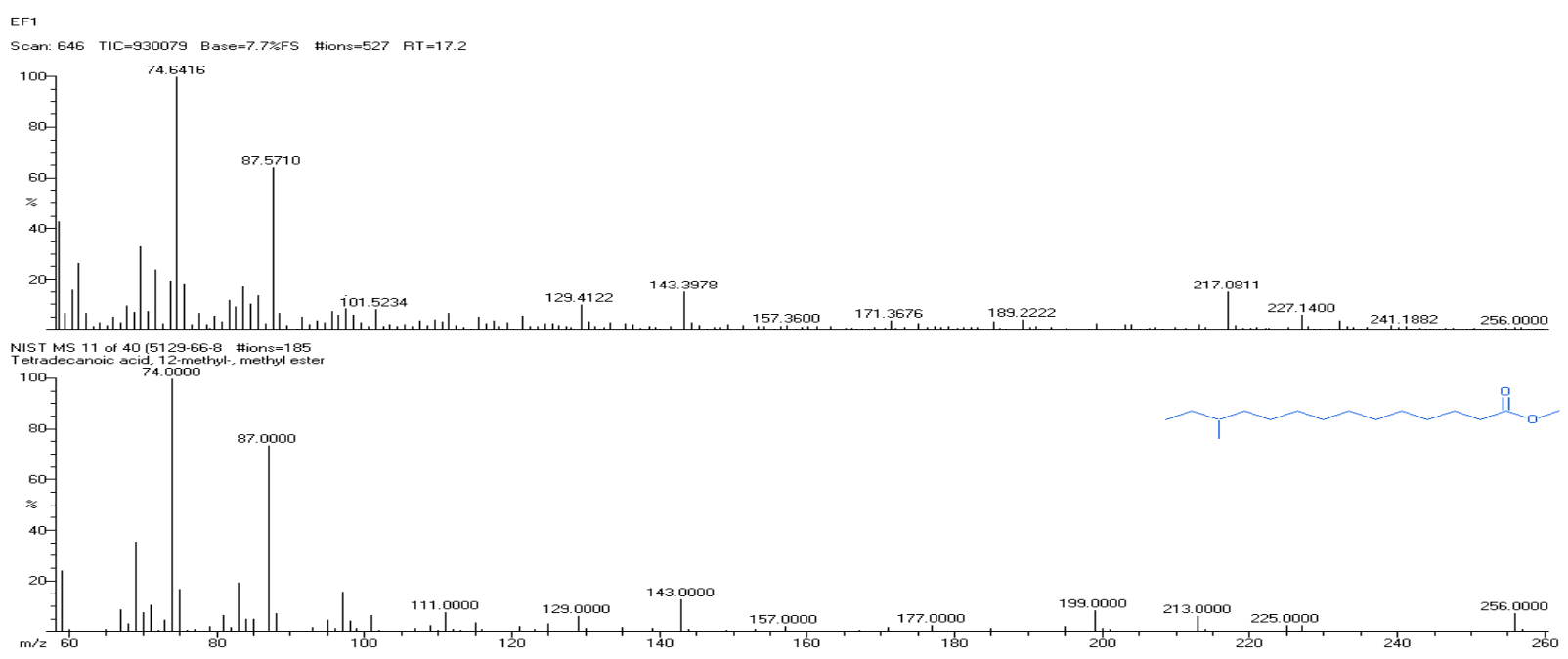

Fig. 4: Structure of tetradecanoic acid, 12-methyl-, methyl ester present in EF1 (Curvularia aeria MTCC-12847) by using GCMS analysis

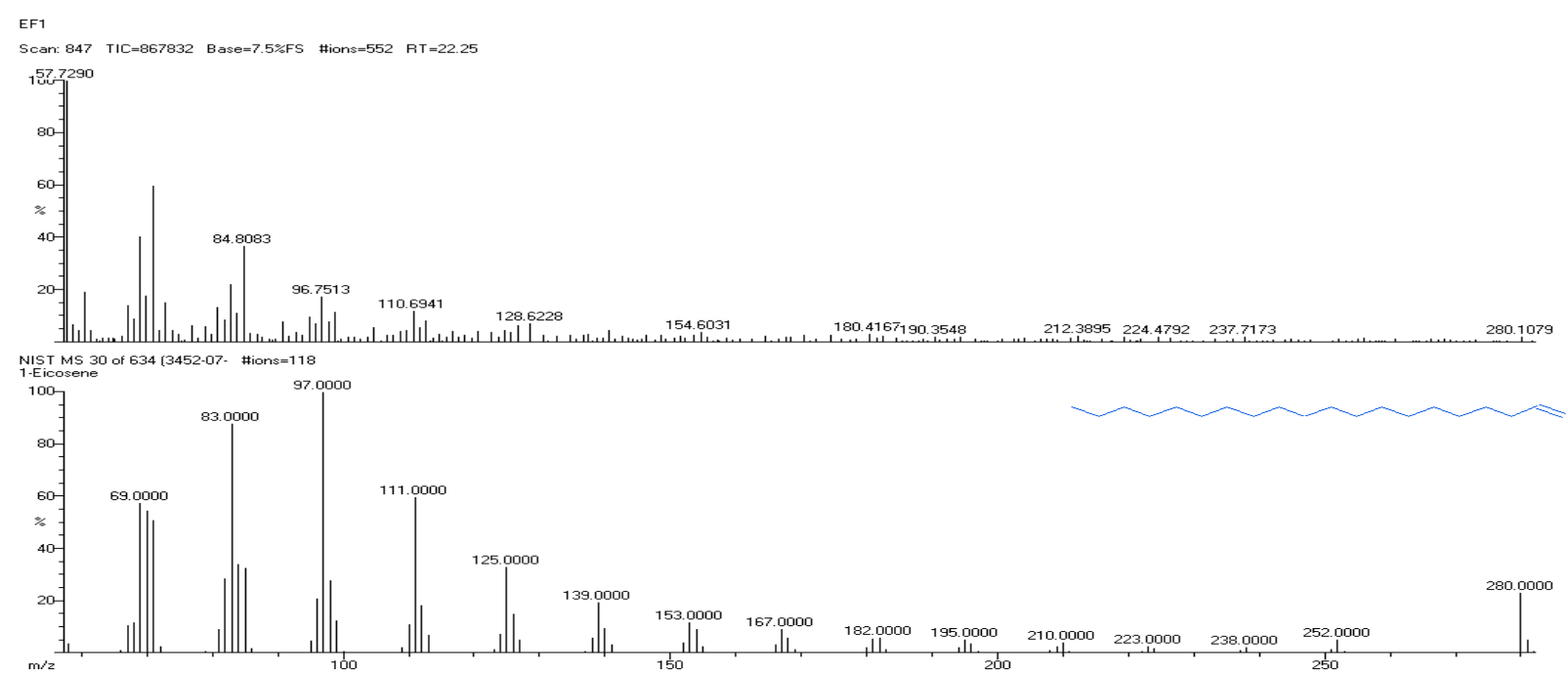

Fig. 5: Structure of 1-eicosene present in EF1 (Curvularia aeria MTCC-12847) by using GCMS analysis

EF1

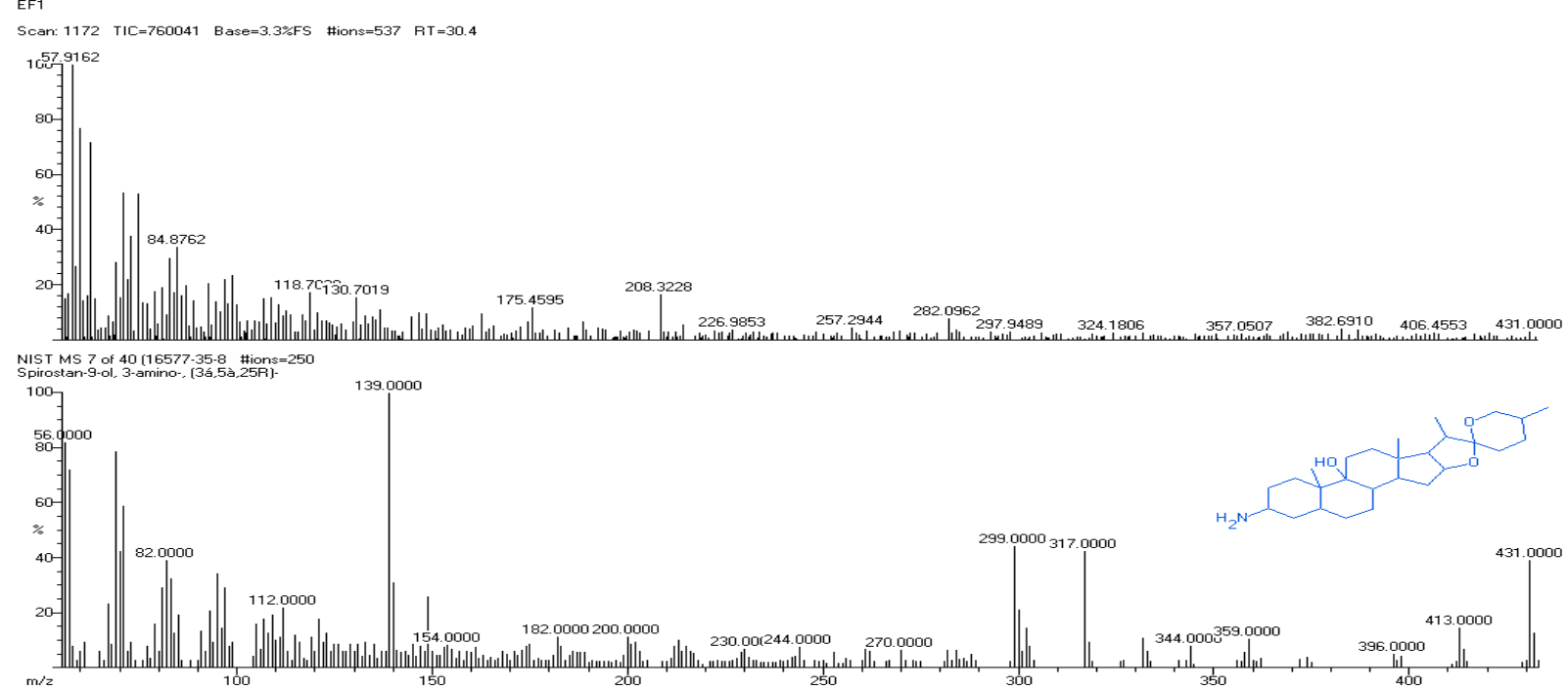

Fig. 6: Structure of spirostan-9-ol, 3-amino-, (3á, 5à, 25R)-present in EF1 (Curvularia aeria MTCC-12847) by using GCMS analysis 
$\mathrm{E}$



Fig. 7: Structure of 9-Amino-6-fluorolepidine present in EF1 (Curvularia aeria MTCC-12847) by using GCMS analysis

EF1

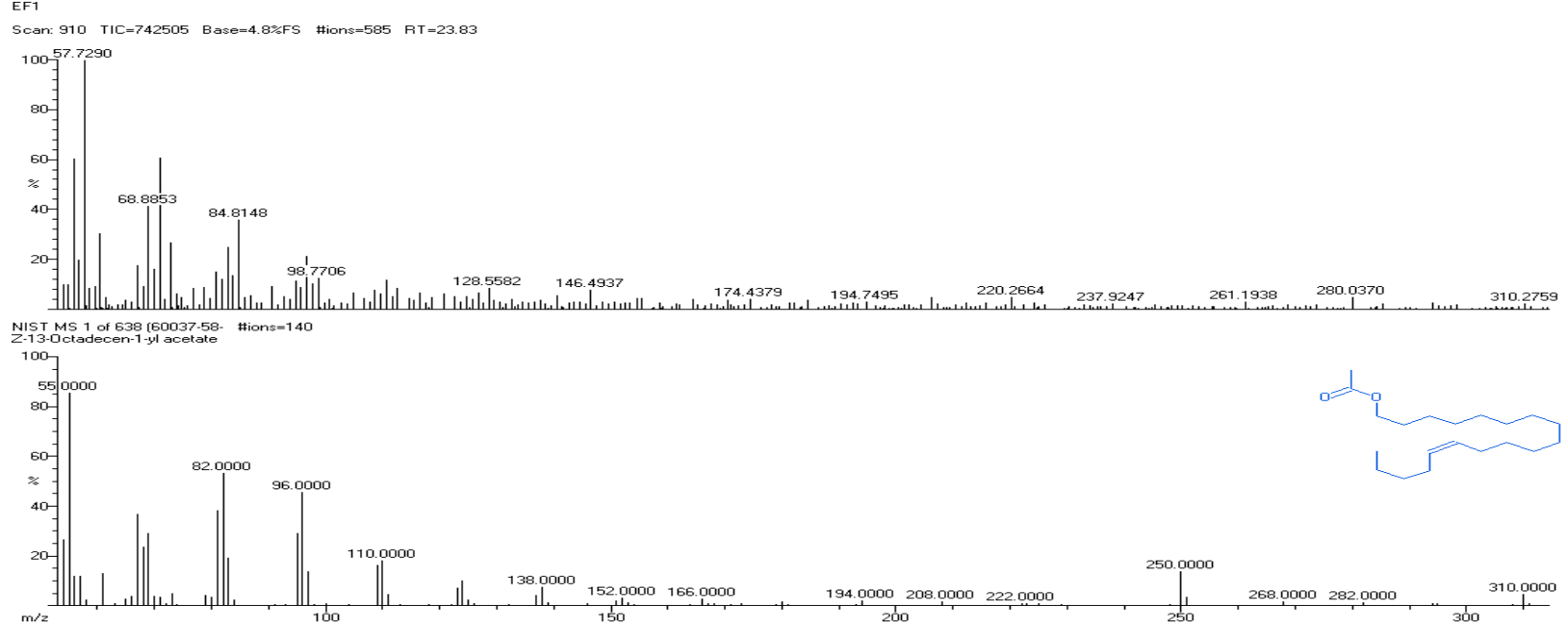

Fig. 8: Structure of Z-13-octadecen-1-yl acetate present in EF1 (Curvularia aeria MTCC-12847) by using GCMS analysis

EF1

Scan: 606 TIC $=739956$ Base $=3.5 \%$ FS \#ians $=532 \quad$ RiT $=16.2$

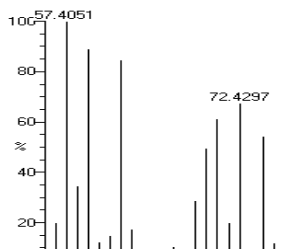



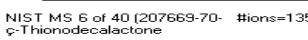

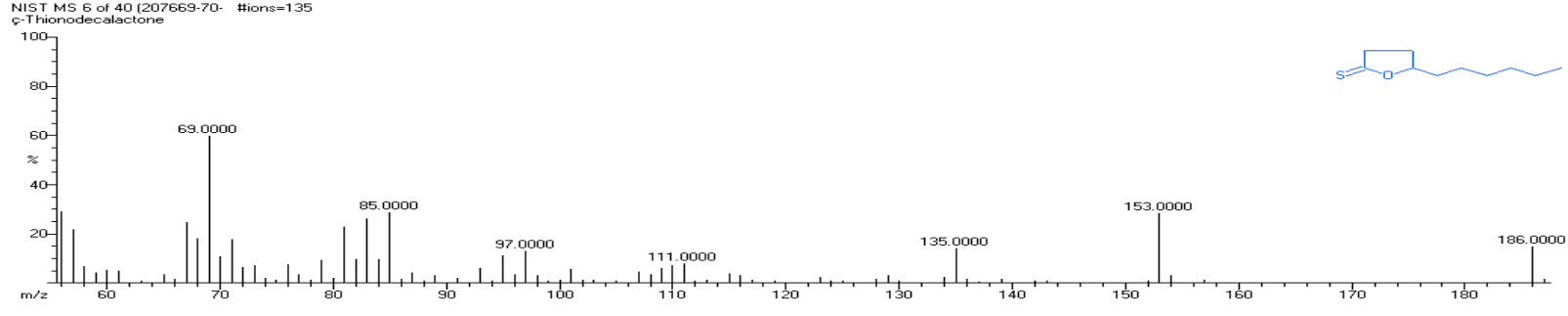

Fig. 9: Structure of ç-thionodecalactone present in EF1 (Curvularia aeria MTCC-12847) by using GCMS analysis 


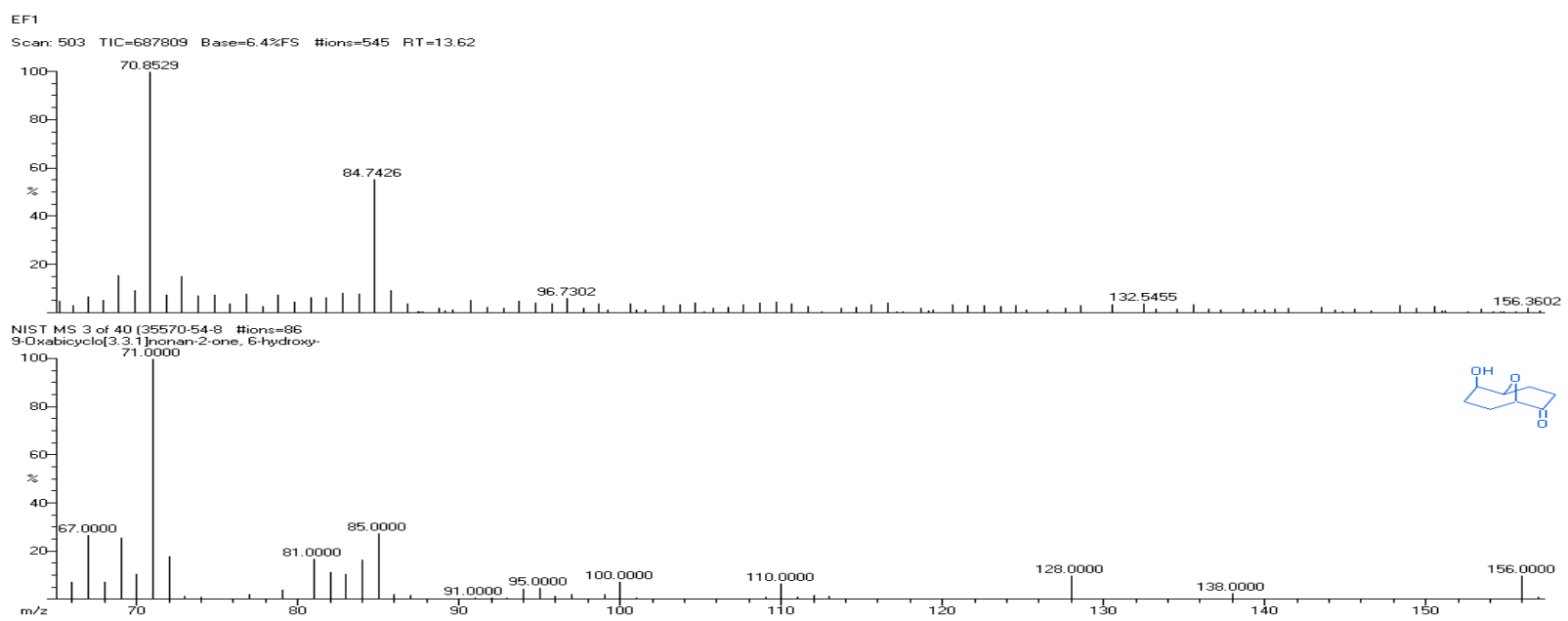

Fig. 10: Structure of 9-oxabicyclo (3.3.1) nonan-2-one, 6-hydroxy-present in EF1 (Curvularia aeria MTCC-12847) by using GCMS analysis

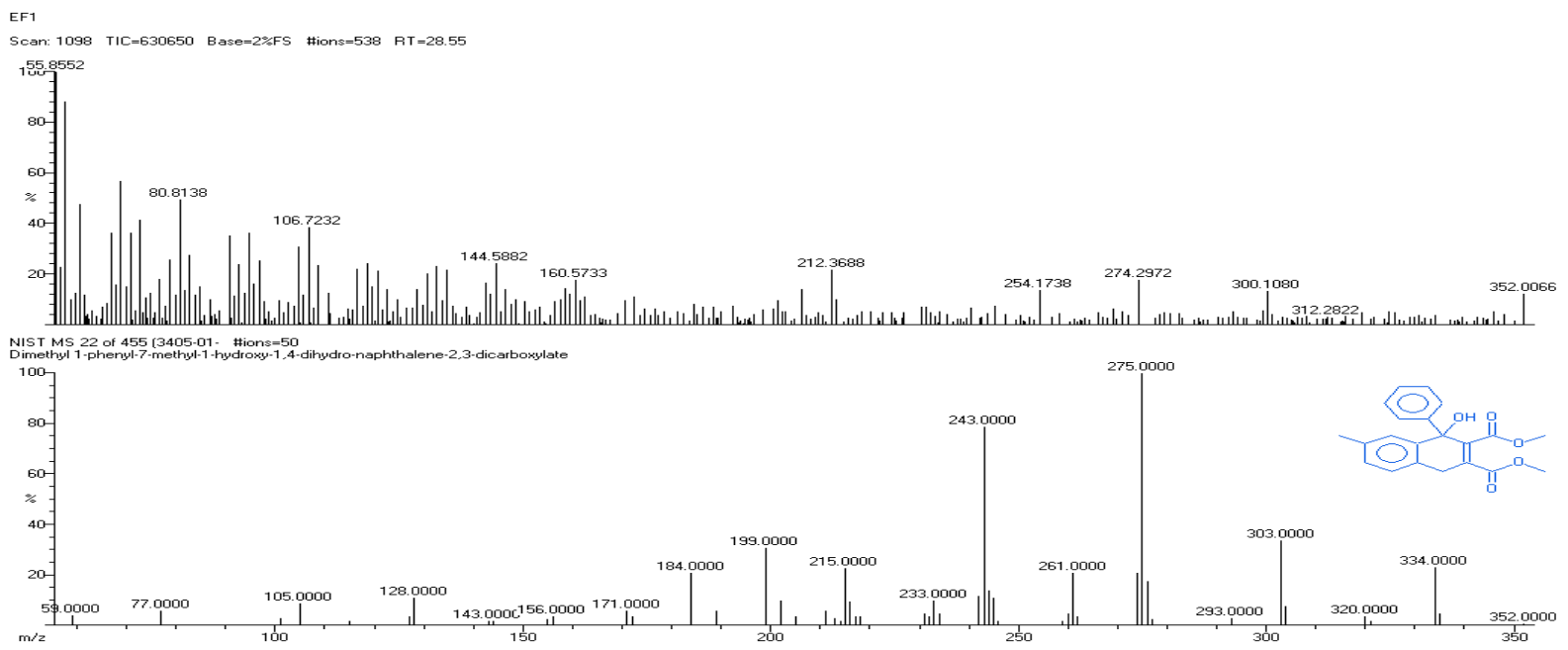

Fig. 11: Structure of dimethyl 1-phenyl-7-methyl-1-hydroxy-1, 4-dihydronaphthalene-2, 3-dicarboxylate present in EF1 (Curvularia aeria MTCC-12847) by using GCMS analysis

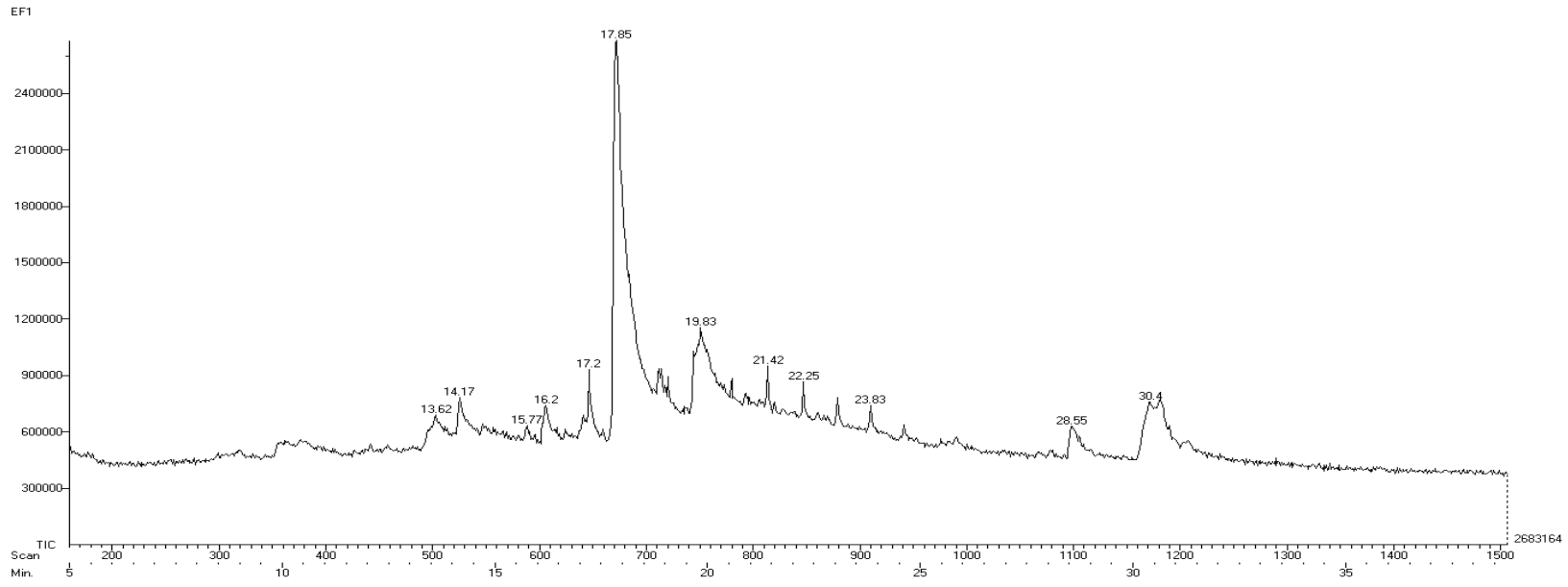

Fig. 12: GCMS chromatogram of EF1 (Curvularia aeria MTCC-12847)

\section{DISCUSSION}

Endophytic fungi, EF1 (Curvularia aeria MTCC-12847) ethyl acetate crude extract showed the presence of major peaks and the components corresponding to the peak. Eleven compounds were detected from the ethyl acetate crude extract of endophytic fungi isolated from the Tribulus terrestris L. The result revealed the presence of Palmitic acid (24.54\%), Hexadecanoic acid, Z-11(10.57\%), E,E-6,8-Tridecadien-2-ol, acetate (8.71\%), Tetradecanoic acid, 12-methyl-, methyl ester (8.50\%), 1-Eicosene (7.93\%), 
Spirostan-9-ol, 3-amino-, (3á,5à,25R)-(6.95\%), 9-Amino-6-fluorolepidine (7.14\%), Z-13-Octadecen-1-yl acetate (6.79\%), çThionodecalactone (6.76\%), 9-oxabicyclo (3.3.1) nonan-2-one, 6hydroxy-(6.29\%), Dimethyl 1-phenyl-7-methyl-1-hydroxy-1,4dihydronaphthalene-2,3-dicarboxylate (5.76\%).

The Gas Chromatography-mass spectrometry (GC-MS) spectrum shows the presence of more long chains hydrocarbons. When the number of carbon atoms increases in the molecule, hydrophilicity is reduced and the lipophilicity is increased. Increased lipophilicity of a drug decreases its transport across intestinal epithelial cells. Furthermore, the presence of compound E, E-6, 8-Tridecadien-2-ol, acetate justify the anticancer potential of endophytic fungi.

\section{CONCLUSION}

The presence of various bioactive compounds justifies the use of endophytic fungi isolated from the Tribulus terrestris $\mathrm{L}$. in various ailments by traditional practitioners.

\section{AUTHORS CONTRIBUTIONS}

All the authors contributed equally to the paper

\section{CONFLICT OF INTERESTS}

Declared none

\section{REFERENCES}

1. Kokate CK, Purohit AP, Gokhale SB. Pharmacognosy. $13^{\text {th }}$ edn. Pune: Nirali Prakashan Publisher; 2007. p. 370.

2. Antonio J, Uelmen J, Rodriguez R, Earnes C. The effects of Tribulus terrestris on body composition and exercise performance in resistance-trained males. Int J Sport Nutr Exerc Metab 2000;10:208-15.

3. Cai $\mathrm{L}, \mathrm{Wu}$ Y, Zhang J, Pei F, Xu Y, Xie S. Steroidal saponins from Tribulus terrestris. Planta Med 2001;67:196-8.

4. Mishra NK, Biswal G, Chowdary KA, Mishra G. Anti-arthritic activity of Tribulus terrestris studied in freund's-adjuvant induced arthritic rats. J Adv Pharm Technol Res 2013;4:41-8.

5. Baburao B, Rajyalakshmi G, Venkatesham A, Kiran G, Shyamsunder A, Gangarao B. Anti-inflammatory and antimicrobial activities of methanolic extract of Tribulus terrestris L. plant. Int J Chem Sci 2009;7:1867-72.

6. Oh JS, Baik SH, Ahn EK, Jeong W, Hong SS. Anti-inflammatory activity of Tribulus terrestris in RAW264.7 cells. J Immunol 2012;88:54-2.

7. Oh HK, Park SJ, Moon HD, Jun SH, Choi NY, You YO. Tribulus terrestris inhibits caries-inducing properties of Streptococcus mutants. J Med Plants Res 2011;5:6061-66.

8. Zhang S, Li H, Yang SJ. Tribulosin protects rat hearts from ischemia/reperfusion injury. Acta Pharmacol Sin 2010;31:671-8.

9. Ivanova A, Serly J, Dinchev D, Ocsovszki I, Kostova I, Molnar J. Screening of some saponins and phenolic components of Tribulus terrestris and Smilax excelsa as MDR modulators. In Vivo 2009;23:545-50.

10. Svetla A, Zlatina G, Maria K, Georgi A, Valentin L, Tsanko M. Antitumor activity of Bulgarian herb Tribulus terrestris L. on human breast cancer cells. J Biosci Biotech 2013;2:25-32.
11. Neychev VK, Nicolova E, Zhelev N, Mitev VI. Saponins from Tribulus terrestris L. are less toxic for normal human fibroblasts than for many cancer lines: Influence on apoptosis and proliferation. Exp Med Biol 2007;232:126-33.

12. Kumar M, Soni AK, Shukla S, Kumar A. Chemopreventive potential of Tribulus terrestris against 7, 12-dimethylbenz (a) anthracene induced skin papillomagenesis in mice. Asian Pac J Cancer Prev 2006; 7:289-94.

13. Bacon CW, White JF. Microbial endophytes. Marcel Dekker Inc, New York; 2000.

14. Petrini O, Fokkema NJ, Van den Heuvel J. Microbiology of the Phyllosphere. Cambridge University Press, Cambridge; 1986.

15. Hallmann J, Quadt-Hallmann A, Mahaffee WF, Kloepper JW. Bacterial endophytes in agricultural crops. Can J Microbiol 1997;43:895-914.

16. Verma VC, Gond SK, Kumar A, Mishra A, Kharwar RN, Gange AC. Endophytic actinomycetes from Azadirachta indica A. Juss.: isolation, diversity, and anti-microbial activity. Microb Ecol 2009;57:749-75.

17. Saikkonen K, Wali P, Helander M, Faeth SH. Evolution of endophyte-plant symbiosis. Trends Plant Sci 2004;9:275-80.

18. Schulz B, Boyle C, Draeger S, Rommert A, Krohn K. Endophytic fungi: a source of novel biologically active secondary metabolites. Mycol Res 2002;106:996-1004.

19. Strobel GA, Daisy B. Bioprospecting for microbial endophytes and their natural products. Microbiol Mol Biol Rev 2003;67:491-502.

20. Fisher PJ, Petrini O. Tissue specificity by fungi endophytic in Ulex europaeus. Sydow 1987;40:46-50.

21. Suryanarayanan TS, Kumaresan V, Johnson JA. Foliar fungal endophytes from two species of the mangrove Rhizophora. Can J Microbiol 1998;44:1003-6.

22. Schulz B, Wanke U, Drager S, Aust HJ. Endophytes from herbaceous plants and shrubs: effectiveness of surface sterilization methods. Mycol Res 1993;97:1447-50.

23. Buatong J, Phongpaichit S, Rukachaisirikul V, Sakayaroj J. Antimicrobial activity of crude extracts from mangrove fungal endophytes. World J Microbiol Biotechnol 2011;27:3005-8.

24. Mohammed A, Imad H, Autosomal STR. From locus information to next-generation sequencing technology. Res J Biotechnol 2013;8:92-105.

25. Kareem MA, Hussein AO, Hameed IH. Y-chromosome short tandem repeat, typing technology, locus information, and allele frequency in the different population. Afr J Biotechnol 2015;14:2175-8.

26. Imad H, Mohammed A, Aamera J. Genetic variation and DNA markers in forensic analysis. Afr J Biotechnol 2014a;13:3122-36.

27. Imad H, Mohammed A, Cheah Y, Aamera J. Genetic variation of twenty autosomal STR loci and evaluate the importance of these loci for forensic genetic purposes. Afr J Biotechnol 2014b;13:1-9.

28. Imad H, Muhanned A, Aamera J, Cheah Y. Analysis of eleven Ychromosomal STR markers in middle and south of Iraq. Afr J Biotechnol 2014c;13:3860-71.

29. Hamza LF, Sabreen AK, Imad HH. Determination of metabolites products by Penicillium expansum and evaluating antimicrobial activity. J Pharmacogn Phytother 2015;7:194-220. 